\title{
Nebulised sodium cromoglycate in recurrently wheezy preschool children
}

\section{J J COGSWELL AND M J SIMPKISS}

Paediatric Department, Poole General Hospital

SUMmARY A double blind crossover study of nebulised sodium cromoglycate in 27 asthmatic preschool children was carried out over a one year period. All subjects had sufficiently severe asthma to have had at least one admission to hospital. The active treatment was sodium cromoglycate $20 \mathrm{mg}$ (in $2 \mathrm{ml}$ ) administered by a nebuliser four times daily. Assessment was made by a diary card and clinical examination. Results were analysed in 24 subjects who completed the study. Statistical analysis allowed for order of treatment and seasonal effects. Significant results in favour of treatment with sodium cromoglycate were obtained for night cough, day activity, percentage of symptom free days, and overall severity of asthma. During active treatment there was no reduction in the rate of admissions to hospital or intravenous drugs used. The wheeze score during the week after an upper respiratory tract infection was not reduced during treatment with sodium cromoglycate.

Nebulised sodium cromoglycate is a tedious prophylactic treatment for the young asthmatic child but is useful when other treatments have failed.

Sodium cromoglycate delivered by Spinhaler can be an effective prophylactic for asthma in children. ${ }^{1}$ Children under 5 years have difficulty using the Spinhaler correctly. To overcome this problem the drug can be administered by a nebuliser and face mask; some reports have claimed that such treatment is effective in the young child. ${ }^{2-8}$ Our experience suggested that not all preschool children responded to nebulised sodium cromoglycate, and as information was scarce we decided to undertake a double blind crossover study for a sufficiently long period to assess benefit. We wanted to find out if nebulised sodium cromoglycate treatment reduced the number of severe attacks of asthma that required admission to hospital. As wheezy exacerbations in the preschool child are often precipitated by respiratory viruses we also examined whether sodium cromoglycate could prevent wheezing in children known to be infected.

\section{Patients and methods}

Twenty seven children (14 boys and 13 girls) entered the trial. Informed consent was obtained from all parents after the study had been explained. Six children withdrew from the study: four due to noncooperation, one to severe exacerbation of disease while taking placebo, and one to spontaneous improvement also while taking placebo. Three of these children took one treatment only; the 24 children who took both test treatments during the course of the trial were included in the analyses of efficacy. The mean age at the start of the trial was 2 years 9 months (range 1 year 2 months -4 years 1 month). All children had regular attacks of asthma of sufficient severity to have required at least one admission to hospital (mean number of admissions before study $2 \cdot 2$ ). In 20 subjects asthma had been present for at least one year before the start of the study. There was a family history of asthma, eczema, or hay fever in parents or siblings of 16 of the 27 subjects. Seventeen of the children yielded at least one positive result ( $3 \mathrm{~mm}$ wheal or more) from prick tests to common allergens.

The trial was double blind and took the form of a crossover study during 12 months. A one month baseline period preceded the crossover trial. For the first six months patients were assigned randomly to receive either active or placebo treatment, after which they changed to the other treatment for the remaining six months. The two treatments were sodium cromoglycate solution $20 \mathrm{mg}$ in a $2 \mathrm{ml}$ ampoule administered four times daily by a nebuliser and a matched placebo (sterile water) packaged in identical ampoules and coded by the manufacturers. A disposable plastic nebuliser driven by a 
portable electric compressor was used. (Acorn 2 nebuliser and Portaneb 40 by Medic-Aid). The system nebulised $2 \mathrm{ml}$ of fluid within 10 minutes. Throughout the 13 months parents completed a daily record card of the child's symptoms (night cough, day cough, day wheeze, day activity, overall severity of asthma, and number of bronchodilator doses given). Symptoms were recorded on a severity scale from 0 (none) to 10 (very severe). Parents were asked to notify the research team of all respiratory infections. At these times the respiratory research nurse visited the child in the home to obtain pharyngeal cells for viral culture. ${ }^{9}$

Parents were assessed by the clinician at the hospital every four weeks. Compliance with the treatment was ensured by unannounced visits by the research nurse to the children's homes. When a child was admitted to hospital in an asthmatic attack an attempt was made to assess the severity of the attack; this was usually performed retrospectively by analysis of treatment given. The number of days in hospital was recorded.

Statistical analysis of the diary card data was by non-linear least squares regression using a model that allowed for seasonal effects and order of treatment (period effects). Seasonal effects were included as a potential source of difference in scores could have been due to the difference between winter and summer months, and this could obscure a real effect of treatment. The estimate of the difference between the two treatments was obtained from the following model: $Y=P_{1}+\left(O R D \times P_{2}\right)+1 / 2 P_{3}$ $\left\{\sin \left(\pi \times\left(\mathrm{TP}-\mathrm{P}_{4}\right) / 6\right)-\sin \left(\pi \times\left(\mathrm{TA}-\mathrm{P}_{4}\right) / 6\right)\right\}+$ error, where

$\mathrm{Y}$ is the observed difference between the two treatments;

$P_{1}$ is the estimated difference between effects of treatment;

$P_{2}$ is the estimated difference between the first and second treatment period;

ORD is negative or positive depending on the order of treatment followed by each particular patient; $P_{3}$ is the estimated amplitude of the seasonal effect with a sign indicating the direction of adjustment; $\mathrm{P}_{4}$ is an estimated value for the seasonal effect shift (the phase of the sine curve); and

TP and TA are the months (from one to 12) in the middle of the period of treatment with placebo and sodium cromoglycate, respectively. The estimate was used, in conjunction with its standard error, to test for significance.

\section{Results}

Most children accepted the treatment well, though some parents found the regular nebuliser treatment tedious. Ten of the 24 patients followed the sequence placebo then active treatment, whereas 14 took the active drug first.

Table 1 shows the mean symptom scores. Adjusted estimates allowing for seasonal and period effects are presented in Table 2. Point estimates of the seasonal effects are shown in Table 3 . Significant results $(\mathrm{P}<0.05)$ in favour of treatment with sodium

Table 1 Information from diary cards* during treatment in 24 children with completed records

\begin{tabular}{lll}
\hline & \multicolumn{1}{l}{ Treatment } & \\
\cline { 2 - 3 } & $\begin{array}{l}\text { Sodium } \\
\text { cromoglycate }\end{array}$ & Placebo \\
\hline Mean (range) night cough score & $0 \cdot 8(0 \cdot 1-3 \cdot 3)$ & $1 \cdot 1(0 \cdot()-3 \cdot 9)$ \\
Mean (range) day cough score & $0 \cdot 8(0 \cdot 0-2 \cdot 5)$ & $1 \cdot 0(0 \cdot()-3 \cdot 3)$ \\
Mean (range) day wheeze score & $0 \cdot 6(0 \cdot()-2 \cdot 2)$ & $0 \cdot 9(0 \cdot()-3 \cdot 8)$ \\
$\begin{array}{l}\text { Mean (range) day activity score } \\
\text { Mean (range) \% symptom free days }\end{array}$ & $0 \cdot 5(0 \cdot()-2 \cdot 1)$ & $0 \cdot 7(0 \cdot()-3 \cdot 9)$ \\
$\begin{array}{l}\text { Mean (range) daily dose of } \\
\text { bronchodilators }\end{array}$ & $0 \cdot(22-90)$ & $50(0-10(0)$ \\
$\begin{array}{l}\text { Mean (range) overall severity of } \\
\text { asthma score }\end{array}$ & $0 \cdot 6(0 \cdot 0-1 \cdot 5)$ & $0 \cdot 8(0 \cdot(1)-2 \cdot 3)$ \\
\hline
\end{tabular}

*Scale for symptom scores: $0=$ none to $10=$ very severe.

Table 2 Diary card scores *after analysis to allow for order of treatment and seasonal effects

\begin{tabular}{|c|c|c|c|}
\hline \multirow[b]{2}{*}{. } & \multicolumn{2}{|l|}{ Treatment } & \multirow{2}{*}{$\begin{array}{l}\text { Difference } \\
\text { (and SEM) } \\
(20 \text { df })\end{array}$} \\
\hline & $\begin{array}{l}\text { Sodium } \\
\text { cromoglycate }\end{array}$ & Placebo & \\
\hline Mean night cough score & 0.77 & $1 \cdot 16$ & $0.39(0 \cdot 18) \dagger$ \\
\hline Mean day cough score & 0.76 & $1 \cdot 05$ & $0.29(0.15)$ \\
\hline Mean day wheeze score & 0.56 & 0.92 & $0.36(0 \cdot 18)$ \\
\hline Mean day activity score & 0.44 & 0.82 & $0 \cdot 38(0 \cdot 14) \dagger$ \\
\hline Symptom free days (\%) & $60 \cdot 7$ & $49 \cdot 6$ & $-11 \cdot 1(5 \cdot 1) \dagger$ \\
\hline $\begin{array}{l}\text { Mean daily dose of } \\
\text { bronchodilators }\end{array}$ & 0.54 & 0.78 & $0.24(0 \cdot 12)$ \\
\hline $\begin{array}{l}\text { Mean overall severity of } \\
\text { asthma score }\end{array}$ & 0.53 & 0.92 & $0.39(0.17) \dagger$ \\
\hline
\end{tabular}

${ }^{*}$ Scale for symptoms scores: $0=$ none to $10=$ very severe.

$+\mathrm{P}<0 \cdot 05$.

Table 3 Estimates of seasonal effects from diary card data

\begin{tabular}{|c|c|c|c|}
\hline \multirow[t]{2}{*}{ Variable* } & \multicolumn{3}{|c|}{ Seasonal effects } \\
\hline & $\begin{array}{l}\text { Amplitude } \\
\left(P_{3}\right)\end{array}$ & $\begin{array}{l}\text { Phase of maximum } \\
\text { symptoms } \\
\left(P_{4}+\text { three months) }\right.\end{array}$ & $\begin{array}{l}\text { Variance } \\
\text { ratio (two } \\
\text { and } 20 \mathrm{df})\end{array}$ \\
\hline Night cough score & 0.55 & February & 1.83 \\
\hline Day cough score & 0.79 & March & $4.96 \dagger$ \\
\hline Day wheeze score & 0.49 & February & $1 \cdot 30$ \\
\hline Day activity score & 0.87 & March & $6 \cdot 22 \dagger$ \\
\hline Symptom free days $(\%)$ & $-17 \cdot 8$ & January & $2 \cdot 67$ \\
\hline \multicolumn{4}{|l|}{ Mean daily dose of } \\
\hline bronchodilators & $0 \cdot 23$ & January & 0.95 \\
\hline Overall severity of asthma & 0.66 & March & $2 \cdot 73$ \\
\hline
\end{tabular}

*Scale for symptom scores: $0=$ none to $10=$ very severe. $+\mathrm{P}<0.05$. 
cromoglycate were obtained for night cough, day activity, percentage of symptom free days, and overall severity of asthma.

No significant difference was found between treatment with sodium cromoglycate and placebo by Wilcoxon's rank sum tests for percentage of days in hospital. Intravenous treatment was required as often in those receiving sodium cromoglycate as those given placebo.

During the study period 24 children developed 25 upper respiratory tract infections while taking placebo and 34 while taking sodium cromoglycate. The viruses isolated during the upper respiratory tract infections were Influenza A, Parainfluenza type 3, and Adenovirus type 2 (isolation rate $15 \%$ ).

A comparison of the average wheeze score for the week after an upper respiratory tract infection with that for the week before infection while taking either sodium cromoglycate or placebo failed to show any ameliorating effects with sodium cromoglycate treatment. Eight patients reported colds during both parts of the study. Three of these showed less increase in wheeze score while taking sodium cromoglycate, and three showed less while taking placebo.

It was impossible to predict which children would respond to sodium cromoglycate on the basis of age, atopic family history, or presence of cutaneous allergy tests. Patients reported some minor symptoms in both parts of the trial, but none were thought to be related to treatment.

\section{Discussion}

This study was conducted over a longer period of time than others reported previously ${ }^{5-8}$ but accords with them by showing that nebulised sodium cromoglycate is superior to placebo as prophylactic treatment for preschool asthmatic children with respect to night cough, day activity, and overall severity of asthma scores. The number of symptom free days was also significantly higher during treatment with sodium cromoglycate. This analysis was included because despite strict selection criteria many patients had low asthma scores during periods of treatment.

Paediatricians are all too familiar with the preschool child who is admitted to hospital with devastatingly severe attacks of asthma precipitated by respiratory infection. It was disappointing that nebulised sodium cromoglycate neither prevented nor modified these severe attacks as the number of admissions to hospital and the need for intravenous treatment of drugs were not reduced during prophylaxis with sodium cromoglycate. The lack of efficacy in preventing wheezy episodes precipitated by virus infection was also shown by no change in the asthma scores during the week after upper respiratory tract infections. The mode of action of sodium cromoglycate may not prevent the mucus plugging and mucosal swelling that characterises obstruction of the airways of these young patients.

The treatment of young children in their homes with nebulised sodium cromoglycate is time consuming and tedious for the parents. Although compliance during the study was good, this is unlikely to be so under clinical conditions. Despite these disadvantages this form of prophylaxis deserves a trial when other treatments have failed.

We thank the children and parents who took part and acknowledge the technical and nursing help of Joan Wignall. We also thank Fisons who supplied drugs and compressors and are grateful to the statistical advice of Mr D F Percy.

\section{References}

1 Silverman M, Conolly NM, Balfour-Lynn L, Godfrey S. Long term trial of disodium cromoglycate and isoprenaline in children with asthma. Br Med J 1972;iii:378-81.

2 Gale A. Nebulised intal in asthma. South Australian Clinics 1972;6:115.

${ }^{3}$ Phelan PD. Disodium cromoglycate in young children with asthma. In: Pepys J, Yamamura J, eds. Intal in bronchial asthma. Loughborough: Fisons, 1974:75.

4 Williams HE, Phelan PD. Administration of disodium cromoglycate to young children. Br Med J 1973;ii:488.

5 Hiller EJ, Milner AD, Lenney W. Nebulised sodium cromoglycate in young asthmatic children. Arch Dis Child 1977;52:875-6.

${ }^{6}$ Geller-Bernstein C, Levin S. Nebulised sodium cromoglycate in treatment of wheezy bronchitis in infants and young children. Respiration 1982:43:292-8.

${ }^{7}$ Miraglia de Giudice M, Capristo A, Maillo N, Apuzzo G. Nebulised sodium cromoglycate for the treatment of asthma in children under five years of age. Modern Problems in Paediatrics 1982;21:122-7.

${ }^{8}$ Henry RL, Hiller EJ, Milner AD, Hodges IGC, Stokes GM. Nebulised ipatropium bromide and sodium cromoglycate in the first two years of life. Arch Dis Child 1984;59:54-7.

${ }^{9}$ Cogswell JJ, Halliday DF, Alexander JR. Respiratory infections in the first year of life in children at risk of developing atopy. $\mathrm{Br}$ Med J 1982;284:1011-2.

Correspondence to Dr J J Cogswell, Poole General Hospital, Poole, Dorset BH15 2JB.

Received 1 March 1985 